\section{Kiwi Hospitals: "Future- Looking" Principles for a Hospital Maturity Model}

HENRIQUE MARTINS (D)

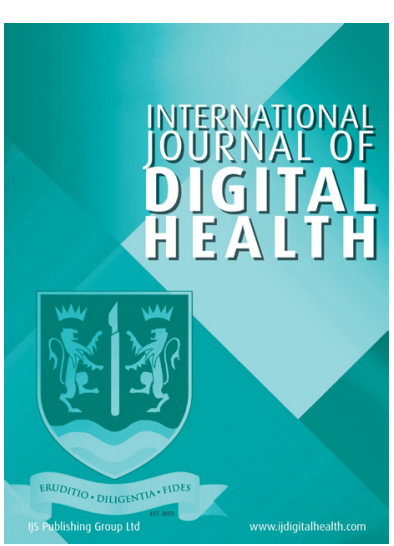

EDITORIAL

\section{ABSTRACT}

Hospitals are, for most human beings, the more visible, historical and futuristic, dramatic and hopeful, side of healthcare. Most hospitals today face criticisms for being too complex to navigate, too risky for elderly and frail people due to nosocomial infections and intolerably high rates of medical error. While seeing the future of hospitals is not possible it is likely that it will mean an ever-incensing use of technology. Changes in hospitals and their internal dynamic have a lot to do with digital health understood in a broader sense. Hospitals are "knowledge organizations". To ensure the best response to the aspirations and raising challenges successful hospitals of the future will be those that combine four elements in an equilibrium. They need to be Knowledgeable, Intelligent, Wise and Interoperable. Managers will need to be more capable of funding the right investments to get to KIWI hospitals. The suggested KIWI framework can be applied as future-looking maturity model principles. The target is a future proof hospital capable of solving old problems and be ready for resilient responses, such as the ones 2020 has shown the world hospitals need and are needed for.

\section{CORRESPONDING AUTHOR:}

\section{Henrique Martins}

Faculty of Health Sciences, University of Beira Interior, Avenida Infante D. Henrique. 6200-506 Covilhã, Portugal; ISCTE-IUL, Lisbon, Portugal

henrique@henriquemartins.eu

\section{KEYWORDS:}

Hospital; Kiwi; Model; Maturity; Digital Health; Healthcare

TO CITE THIS ARTICLE: Martins H. Kiwi Hospitals: "Future-Looking" Principles for a Hospital Maturity Model. International Journal of Digital Health. 2021; 1(1): 13, 1-3. DOI: https://doi.org/10.29337/ijdh.38 
Hospitals are, for most human beings, the more visible, historical and futuristic, dramatic and hopeful, side of healthcare. From large, multi-building facilities with academic as well as advanced research components, to small district or local homecare where a proximity-type healthcare can be provided. Most hospitals today face criticisms for being too complex to navigate, too risky for elderly and frail people due to nosocomial infections and intolerably high rates of medical error. They are accused of being too inhuman, cool and frightening, too technical and difficult to reach due to financial or complex referencing systems.

Many good examples of large and small institutions around the world which are making significant steps to eliminate these causes of criticism exist. They range from Patch Adams' type of work [1] to the rigorous "Clinical Governance" initiatives in the UK [2]. From highly digital Kaiser Permanente or artificial intelligence (AI) hospital projects funded by the European Commission, to the extraordinary example of Toyota Production System applied to the $\mathrm{Ng}$ Teng Fong General Hospital in Singapore, a prime exemplar of lean in healthcare [3]. These illustrate different developments for hospitals. While seeing the future is not possible it is likely that it will mean an intense use of digital health. I do not mean we cannot foresee physical appearance, size, or even what medical specialities will prevail. I mean their organizational culture and their strategies to deal with workforce, information, facilities and equipment, and, ultimately, care processes. Changes in these aspects of hospitals and their internal dynamic have a lot to do with digital health understood in a broader sense. If one could put this "essential spirit" into one word, the difference between ancient monastery hospices and current hospitals would be: Science. Similarly, between today's hospital institutions, albeit their heterogeneity, and future hospitals this "essential spirit" will be they possess of Hybrid Intelligence and

\section{Wisdom.}

Hospitals are, or should resemble, Nonaka's "knowledge organizations" [4,5] as they are humanresource intensive spaces where most of what happens depends on highly skilled doctors, nurses, pharmacists and all other professionals. Yet few are structured according to clinical pathways. Hospitals offer and deliver knowledge intensive services such as an eye cataract surgery or a brain electro-implant therapy. They must be quality focused, and error cognizant and avoidant or adverse. Only by doing so will they improve, gain and regain citizens' trust. This remains difficult in most organizations, but new times have to bring about change if we are to advance into Digital Healthcare Systems an opinion I have expressed previously [6].

Intelligence is no longer a human exclusive, as Humans have set on a serious journey to create AI systems and agents. Wisdom is a long-time human exclusive attainment. It is now critical to balance incredible technological possibilities that bend the limits of ethics, humanity, and dignity. The question of what organizational wisdom is and how can it be usefully conceived need to be answered. Multiple information systems, and the need for interconnected organizations and interdependent care process, remind "the hospital" that it is often not more than a multitude of "smaller, often divided" mini-hospitals or departments, in an ecosystem of regional, national and now, more than ever, global public health interdependency. To ensure the best response to the aspirations and raising challenges hospitals of the future are those that combine four elements in an equilibrium. They need to be Knowledgeable, Intelligent, Wise, and Interoperable.

Knowledgeable - Hospitals will need to increasingly operate and require the highest degrees of science and technology combined with practical expertise which is still required. The usage of Clinical Decision Support tools as well as extensive clinical pathways structuring of services will be paramount.

Intelligent - Usage of AI in basic medicine procedures (in robotic surgery; or in imaging or genetics, for example), but also in Intelligent Hospital Management systems. This will require a revision of how to explore and mingle the Natural Intelligence (NI) of existing health staff.

Wise - Only people can be wise. Wisdom is still a human prerogative yet trust and ethics are needed at the "deeper and transversal levels" of the organization. Trust and Digital Ethics reinforcing structures and processes will need to become their core competencies, as technical and scientific potential to do harm or "bad" is immensely increasing.

Interoperable - A term often associated with information technology (IT). While IT interoperability, standards use, and Big Data spaces for exploiting the value of secondary and tertiary data use remain necessary and difficult. Interprofessional teams and inter-organizational Virtual Competence Centre are key features of KIWI hospitals in their struggle to interoperate healthcare inside and inside-out.

Managers will need to be more capable of funding the right investments to get to KIWI hospitals. Not just beds and drugs, wages and surgical material. Intangible assets like culture development, reflection processes, excellence and performance appraisal systems, just to name a few, will be essential to attain the level of KIWI maturity needed for hospitals in the future.

To an organization it is important to consider continuous organizational improvement as a key factor of core business, and it has been shown that an organizational maturity framework would be helpful in creating a more objective and systematic approach to an improvement culture and at the same time utilizing a fully consistent process [7]. The KIWI framework 
can be applied as a future-looking maturity model. In several knowledge areas the identification and creation of maturity models (for example: maturity grids and capability maturity model (CMM) [8]) has been very useful. They allow the establishment of a set of evaluation tools, methods and procedures regarding good management of organizations but also whether they are "MATURE" for something. They serve to highlight their weaknesses, establish opportunities to reach improvements in certain areas, which can become to a strength and not a liability [9]. The target is a future proof hospital capable of solving problems that has made us loose human lives over the last 60 years due to medical error [10], misdiagnose or lack of knowledge retention, but also be ready for resilient responses, such as the ones 2020 has shown the world hospitals need and are needed for.

\section{COMPETING INTERESTS}

The author has no competing interests to declare.

\section{AUTHOR AFFILIATIONS}

Henrique Martins (D) orcid.org/0000-0001-7535-5103 University of Beira Interior, Faculty of Health Sciences, Covilhã, Portugal;

ISCTE-IUL, Lisbon, Portugal

\section{REFERENCES}

1. Patch adams Gesundheit Institute [Internet]. Accessed on 24th March 2021 from: https://www.patchadams.org/ patch-adams/.

2. Price T, Tredinnick-Rowe J, Walshe K, Tazzyman A, Ferguson J, Boyd A, et al. Reviving clinical governance?
A qualitative study of the impact of professional regulatory reform on clinical governance in healthcare organisations in England. Health Policy (New York). 2020 Apr 1; 124(4): 446-53. DOI: https://doi.org/10.1016/j. healthpol.2020.01.004

3. Rotter T, Plishka C, Lawal A, Harrison L, Sari N, Goodridge D, et al. Lean Management What Is Lean Management in Health Care? Development of an Operational Definition for a Cochrane Systematic Review. Eval Health Prof. 2019; 42(3): 366-90. DOI: https://doi.org/10.1177/0163278718756992

4. Nonaka I. A Dynamic Theory of Organizational Knowledge Creation. Organ Sci. 1994; 5(1): 14-37. DOI: https://doi. org/10.1287/orsc.5.1.14

5. Nonaka I. The Knowledge-Creating Company. Harvard Business Review [Internet]. 2007; (July-August). Accessed on $24^{\text {th }}$ March from from: https://hbr.org/2007/07/theknowledge-creating-company.

6. Martins H. Digital Healthcare Systems. Heal J [Internet]. 2020; 20(4): 290-3. Accessed on $24^{\text {th }}$ march 2021 from: https://healthmanagement.org/c/healthmanagement/ issuearticle/digitalhealthcare-systems.

7. Hartono B, Wijaya DF, Arini HM. The impact of project risk management maturity on performance: Complexity as a moderating variable. Int J Eng Bus Manag. 2019; 11: 1-16. DOI: https://doi.org/10.1177/1847979019855504

8. Maier AM, Moultrie J, Clarkson PJ. Assessing Organizational Capabilities: Reviewing and Guiding the Development of Maturity Grids. IEEE Trans Eng Manag. 2012; 59(1): 138-59. DOI: https://doi.org/10.1109/ TEM.2010.2077289

9. Oliveira MA, Lopes I. Evaluation and improvement of maintenance management performance using a maturity model. Int J Product Perform Manag [Internet]. 2019; 69(3): 559-81. DOI: https://doi.org/10.1108/IJPPM-07-2018-0247

10. Kohn LT, Corrigan JM, Donaldson MS. To Err is Human. Kohn LT, Corrigan JM, Donaldson MS (eds.). Washington, DC; 2000.

TO CITE THIS ARTICLE:

Martins H. Kiwi Hospitals: “Future-Looking” Principles for a Hospital Maturity Model. International Journal of Digital Health. 2021; 1(1): 13, 1-3. DOI: https://doi.org/10.29337/ijdh.38

Submitted: 30 January 2021 Accepted: 22 May 2021 Published: 02 June 2021

\section{COPYRIGHT:}

(c) 2021 The Author(s). This is an open-access article distributed under the terms of the Creative Commons Attribution-NonCommercial 4.0 International License (CC-BY-NC 4.0), which permits unrestricted distribution, reproduction and adaptation in any medium, provided the original author and source are credited, and that the material is not used for commercial purposes. See https://creativecommons.org/licenses/by-nc/4.0/.

International Journal of Digital Health is a peer-reviewed open access journal published by IJS Publishing Group. 